Bond University

Research Repository

\title{
Registered geographical indications
}

\section{Between intellectual property and rural policy - Part 1}

Van Caenegem, William

Published in:

Journal of World Intellectual Property

DOI:

10.1111/j.1747-1796.2003.tb00237.x

Licence:

Other

Link to output in Bond University research repository.

Recommended citation(APA):

Van Caenegem, W. (2003). Registered geographical indications: Between intellectual property and rural policy Part 1. Journal of World Intellectual Property, 6(5), 699-719. https://doi.org/10.1111/j.1747-1796.2003.tb00237.x

\footnotetext{
General rights

Copyright and moral rights for the publications made accessible in the public portal are retained by the authors and/or other copyright owners and it is a condition of accessing publications that users recognise and abide by the legal requirements associated with these rights.
}

For more information, or if you believe that this document breaches copyright, please contact the Bond University research repository coordinator. 


\section{Bond University}

\section{ePublications@bond}

Law Faculty Publications

Faculty of Law

September 2003

\section{Registered Geographical Indications : Between Intellectual Property and Rural Policy - Part I}

William van Caenegem

Bond University,william_van_caenegem@bond.edu.au

Follow this and additional works at: http://epublications.bond.edu.au/law_pubs

\section{Recommended Citation}

William van Caenegem. (2003) "Registered Geographical Indications : Between Intellectual Property and Rural Policy - Part I" , .

http://epublications.bond.edu.au/law_pubs/3 


\title{
Registered Geographical Indications
}

\author{
Between Intellectual Property and Rural Policy - Part I* \\ William van CAENEGEM ${ }^{+}$ \\ Associate Professor of Law \\ Bond University \\ Queensland, Australia.
}

\section{INTRODUCTION}

The use of geographical terms ${ }^{\mathbf{1}}$ in association with goods is common. But uses vary in crucial ways. At one end of the spectrum, a geographical term may be used simply to indicate the ultimate origin of goods: made in Australia, made in Germany, made in Taiwan. Such use does not intend to indicate anything about the characteristics of the goods. ${ }^{2}$ At the other end of the spectrum lies the use of geographical terms in a manner which says nothing about either the geographical origin of the goods or their characteristics: Cote d'Or for chocolate, Mont Blanc for pens. ${ }^{3}$ In the latter case, the use of the term does not intend to indicate or guarantee the geographical origin, but the commercial origin of the goods - i.e. by whom they are provided.

The misuse of geographical terms in trade gives rise to various legal remedies. At one end lies an action for misrepresentation ${ }^{4}$ against a trader whose use of the term misleads consumers about their geographical origin: goods marked "Made in Japan" that are actually made in Taiwan, for instance. ${ }^{5}$ At the other end lies an action for infringement of a registered trade mark incorporating a geographical term: against a rival trader for attaching the mark Mont Blanc to pens, for instance. So if the use of the term falsely implies something to the consumer about the geographical origin of goods, the

\footnotetext{
* This article is published in two parts; Part I will appear in the November 2003 issue of The J.W.I.P.

+ Many people have assisted me during my research for this article. At the World Intellectual Property Organization (WIPO) in Geneva Matthijs Geuze, Denis Croze, Marcus Hopperger and Antony Taubman kindly made time to answer some of my questions. At the World Trade Organization (WTO) Adrian Otten, at the Max-Planck Institute in Munich Roland Knaak, at Canberra Toni Harmer of the Department of Foreign Affairs and Trade, and Tony Battaglene of the Australian Winemakers Federation, and at the European Union (EU) Directorate General for Trade in Brussels Antonio Berenguer did the same. Both Bond University Law School and the Law Program of the Research School of Social Sciences at the Australian National University (ANU) provided resources. My thanks are also due to Robert Burrell of the Australian Centre for Intellectual Property in Agriculture at the ANU, Faculty of Law, for his helpful comments on an earlier draft of this article. This article represents the author's views, and not those of any other person or institution mentioned here.
}

1 I use the expression "geographical term" rather than place name, because of its wider import, including natural geographical features as well as names of districts, conurbations, towns, villages, etc.

2 Although even such use may indirectly imply something about the quality; goods made in Germany may have a general reputation for quality and durability, for instance.

3 That is not to say that the term implies nothing at all. Mont Blanc may suggest the "pinnacle" of pens, an implication which is derived from its geographic significance.

4 In some jurisdictions, an action for unfair competition, or for misleading and deceptive conduct in trade.

5 In Australia see, for example, Siddons Pty Ltd. v. The Stanley Works Pty Ltd., (1990) 18 IPR 630. 
remedy lies in the realm of an action for misrepresentation. The use, in terms of geography, is not fanciful, as is the case with registered trade marks, but descriptive - it says something about the goods in and of itself. ${ }^{6}$

Crucial to the distinction between misrepresentation and registered trade-mark infringement is the significance consumers attach to the geographical term. ${ }^{7}$ If it is used in a manner shorn of any geographical meaning, then the remedy lies in the realm of registered trade-marks laws. The term's use is fanciful; it does not identify the geographical origin of the goods in and of itself, but rather the trade origin of goods. If the registered mark informs the consumer about the qualities of the marked goods, ${ }^{8}$ it does this only indirectly; not because of the descriptive meaning of the term but because consumers have come to associate certain qualities with an identifiable trade source.

The current international debate revolves around the European Union's (EU) proposals for the expansion of a hybrid system, that of "registered geographical indications (GIs)", which already exists under municipal and EU laws. Such registered GIs fulfil two functions: they guarantee both the geographical origins of goods and certain qualities or characteristics of goods in relation to which the GI is used. 9 They cannot be registered as ordinary trade marks because they are descriptive rather than distinctive; and arguably, an action in misrepresentation is not a sufficient remedy because the terms are guaranteed to do more than just identify geographical origins, they also assure consumers, by the imposition of separate product standards and controls, of the characteristics of the goods concerned. ${ }^{10}$

Registered GI systems of this kind require a priori geographical delineation and setting of the quality standards to be observed within delineated regions. From that perspective such regulatory systems are instruments of rural and agricultural policy as well as perhaps belonging in the category "intellectual property". For a system of registration of GIs that only guarantees geographical origin and not additional compliance with product standards, the availability of an action for misrepresentation may be a perfectly viable alternative. However, actions for misrepresentation in relation

6 An action for misrepresentation requires proof of reputation and of some degree of deception of consumers as to true geographical origin. But registered trade-mark infringement is actionable without any proof of reputation or deception of consumers if the registered mark is used on the same kind of goods.

7 In some cases a sign rather than a term, for instance a bear for Berne, Switzerland, or the Eiffel Tower for Paris, France.

8 A registered trade mark incorporating a geographical term is capable of distinguishing the goods of one trader from those of another trader, rather than the goods of one region from the goods from another region. Broadly speaking, the trader is the registered owner of the registered trade mark. Again, that the use of the term is fanciful does not mean it is without meaning; the trade origin of goods can indirectly signal the characteristics of the goods to consumers who have learned by experience that goods with the mark have certain consistent qualities. But the trade mark does not in itself, and not necessarily by implication, indicate anything about the quality or characteristics of the goods.

9 To use more technical terms, they are more than mere indications of source.

10 This is the EU model of GI registration, with origin and quality requirements enforced. The eponymous example is the term "Champagne". Used in relation to wine, it indicates not only a wine from the Champagne region of France, but also a sparkling wine of a certain character (dry rather than sweet) made with consistent methods. 
to geographical terms are, in addition to the uncertainties common to all such actions, also subject to uncertainty about proper geographical delineation. ${ }^{11}$ For that reason, it may be rational, at the very least, to combine the availability of an ordinary action for misrepresentation with a system of a priori delineation of relevant geographical areas.

The term "geographical indication" is used in the context of regulatory regimes with rather varied characteristics ${ }^{\mathbf{1 2}}$ In particular, some registration regimes do not require the imposition of independent product standards. ${ }^{13}$ The term "registered geographical indication" is used throughout this article to refer to a registration model requiring both proof of geographical origin and strict observance of product standards. The object of this article is to assess the theory and policy goals of registered GIs along the lines of existing EU regulations and analogous World Trade Organization (WTO) provisions and proposals ${ }^{14}$ Crucial characteristics are set out first below. ${ }^{15}$ The discussion is limited to the use of registered GIs for foodstuffs, i.e. in an agricultural context.

For the sake of this article then, registered GIs are geographical names (direct GIs), or names that are closely associated in consumers' minds with identified geographical areas (indirect GIs), used in relation to foodstuffs that:

- prior to registration, are not the ordinary term used to describe all foodstuffs of a certain kind;

- indicate that the foodstuffs originate in the area identified;

- indicate that the foodstuffs have been produced, processed or prepared in accordance with specifications that apply to all foodstuffs of that kind produced in that area.

11 In other words, it does not provide a priori rules as to how regions are delineated and who falls within a region and has an entitlement as a result.

12 The terms are used in various international instruments and also in the domestic legislation of a number of countries, with varying definitions and legal effects. For an account of international instruments, see Standing Committee on the Law of Trademarks, Industrial Designs and Geographical Indications, Eighth Session (SCT 8/4), Document SCT/6/3 Rev.onGeographical Indications: Historical Background, Nature of Rights, Existing Systems for Protection and Obtaining Protection in other Countries, prepared by the Secretariat; and for an example of use of the term in domestic law, see the Australian Wine and Brandy Corporation Act 1980 (Cth). The terms cover rather more than is immediately apparent; this is the source of some confusion and uncertainty at the level of international negotiations. For instance, some terms are "indirect" GIs, i.e. not actual geographical terms, but other words that have become closely associated with a certain geographical area over time, such as, for instance, feta, a non-geographical term associated with certain cheese-producing regions in Greece.

13 The most long-established, common and well known registration systems are concerned with GIs for wine, but even these are quite varied. Other registration systems are related to foodstuffs, of which cheese is a prime example. In some countries registration of industrial goods is also possible, e.g. in France.

14 For the purpose of investigating the theoretical underpinnings of GI registration, little can be gained by comparing the different models used around the world first, or by entering into the detail of the terminological debate. The French and European systems of GI registration are dealt with in more detail below, as is the system in Australia.

15 The various elements being derived from the French and EU Models of GI registration, in particular appellations of origin/protected appellations (AOC/QP ) in France and protected designations of origin/protected geographical indications (PDO/PGI) under Regulation 2081/92 in the EU, and the provision of the WTO Agreement on Trade-Related Aspects of Intellectual Property Rights (TRIPS) as well as recent proposals in that forum. 
The above specifications must be certified and enforced by a public body, and the geographical term concerned must be officially registered as a result of the certification.

The principal legal characteristics are as follows:

- GIs can only be registered in the name of a collective or organization;

- the collective or organization must represent producers of the foodstuffs within the area identified;

- the ownership of GIs cannot be transferred or assigned;

- GIs cannot be licensed to persons outside the area of the registered GI;

- GIs need not have an existing reputation, or actually be used or intended to be used either to obtain registration or to retain registration, and all the rights flowing from registration;

- GIs can never become generic once registered;

- only a member of the relevant collective or organization is entitled to use the GI, in relation to the foodstuffs for which it is registered, and then only in accordance with regulations concerning the use of the GI adopted by the collective or organization that owns the GI, as certified and enforced by the relevant public body;

- no other person is entitled to use the GI or any translation, imitation, evocation or modification of the GI, in association with the kind of goods for which it is registered, in any circumstances;

- no other person is entitled to use the GI in any way, in association or in relation to goods of any kind, in a manner that is liable to convey a false impression, confuse or mislead consumers as to the true origin of a product.

\section{PROPRIETARY PROTECTION FOR REPUTATION}

\section{A. GIs as Intellectual Property}

From an intellectual property policy perspective, registered GIs are primarily concerned with the protection of reputation adhering to distinctive signs, and against misrepresentations and consequent diversion of trade and dilution. But the rights in registered GIs have many of the hallmarks of a property right, as opposed to a mere right of action. ${ }^{16}$ GI registration is an a priori system of proof of validity and entitlement. Registration is invariably associated with proof of ownership, and thus property -

16 That is, rights with a broader application, such as actions for misleading and deceptive conduct, whether statutory or based on passing-off, actions for unfair competition, or competition deloyale, and the like. 
although in this case collective rather than private property. Whatever the answer to the theoretical question: "Is a registered GI (intellectual) property?" may be, the essential point is that the a priori rights derived from registration are far more extensive than a right of action for misrepresentation - easily justified in terms of honest trade and consumer protection. Therefore, it is important to critically evaluate the theoretical underpinnings of those rights.

In terms of a more precise analogy, registered GIs have many structural attributes in common with registered trade marks. Both are concerned with goodwill. The prohibition on the use of either on like goods is absolute; once registered, proof of reputation is not required, nor does the plaintiff need to show deception, confusion or the like. Ownership is determined by the Register. Rights over GIs are not limited in time, as is also the case with registered trade marks.

\section{B. Policy and the Analogy with Registered Trade Matters}

Nonetheless, there are significant differences as well. The registered GI system has an additional element of State intervention in the organization of production absent in registered trade-marks law. Furthermore, registered GIs are generally concerned with real names of real places. So, registered GIs are not a form of registered trade mark, even if one can argue that collective or certification trade marks can perform the same function. ${ }^{17}$ The critical substantive difference is that registered GIs are descriptive of real places which registered trade marks cannot be. As Dawson points out, "trademark law places geographical indications within the public domain." 18

The critical differences in terms of legal character lie in the:

- nature of ownership (private $v$. collective) and rights to assign and license;

- character of the prohibition of unauthorized use;

- use and reputation; and

- the genericness defence. ${ }^{19}$

Many of these differences ultimately derive from the fact that trade-marks law is a dynamic system, whereas the registered GI system is static. Registered trade-marks law envisages that terms can move between the private sphere of property rights and the

17 The common-law jurisdictions tend to favour the use of certification or collective marks, whereas the civil-law jurisdictions of Europe have a more established tradition of relying on registration of GIs.

18 See N. Dawson, Locating Geographical Indications - Perspectives from English Law, 90 Trademark Reporter 590, 2000, at 601. However, that is only the case where the geographical term says something about the origin of the goods. If the use of the term is fanciful and neither informative nor misleading as to geographic origin (as opposed to commercial origin), the GI may be registered as a trade mark, within the normal statutory parameters.

19 As to distinguishing trade marks and GIs, see also F. Addor and A. Grazioli, Geographical Indications beyond Wines" and Spirit - -A Roadmap for a Better Protection for Geographical Indications in the WTO TRIPS Agreement, 5 J.W.I.P. 6, November 2002, 865, at 869. 
public sphere of ordinary descriptive language. ${ }^{\mathbf{2 0}}$ Exclusive rights to use GIs, on the other hand, are reserved for ever to the inhabitants of the area concerned. Arguably, as long as a place exists and its name exists the inhabitants of that place should not be deprived of their exclusive right to use thatname in association with the goods they produce and sell. ${ }^{21}$ Whether or not they use the term for a certain period, or it is adopted by others to describe certain goods is then theoretically irrelevant, although it may be politically unavoidable. ${ }^{22}$ It is because of this descriptive connection with the physical environment that registered GIs are different from registered trade marks.

Irrespective of the differences, however, because of common features it makes sense to examine the policy grounds for the grant of property rights in trade marks, and adapt them to the registered GI environment. This is even more the case given the paucity of literature on specific GI law and theory. ${ }^{23}$

\section{Consumer Search-Cost Reduction}

There are various strands in the literature concerning the economic and industrial policy goals of trade-mark registration, or in other words, concerning the grant of property rights in distinctive signs that signal the trade origins of goods or services. The most wellestablished justification is "search-cost reduction" for non-testable or experience goods, i.e. goods that cannot be tested before purchase, and the consumer having to rely on experience to select a purchase in the presence of heterogeneity. ${ }^{\mathbf{2 4}}$ Trade marks permit consumers to recognize goods as coming from the same source as goods bought previously, and whose characteristics they prefer, thus reducing search-costs. To ensure that the signal performs this function reliably and consistently, it is necessary both to regulate the dealings of the legitimate owner with the trade mark, and to prohibit imitation of the trade mark. It is also required that the trade mark be distinctive,

20 For a linguistic appraisal of trade-marks law see R. Shuy, Linguistic Battles in Trade Mark Disputes, Palgrave, New York, 2002.

21 Or at least for as long as the place or place name remains in existence. That some GIs are accepted in sortie .jurisdictions and under some international instruments as generic is, from this perspective, an unfortunate accident of history, and not to be seen as theoretically irreversible.

22 Addor and Grazioli, sups'a, footnote 19, stress that loss of rights for GIs because of descriptiveness (or genericness) makes little sense because: "[a GI] is by definition descriptive because a geographic name denotes the geographical origin of the product it identifies." (at 871). However, think of such terms as a frankfurter (sausage), Bermuda shorts, or the term "panama" for a style of headwear. Descriptive of a place is not the same as descriptive of goods.

23 See, nonetheless, S. Escudero, International Protection of Geographical Indications and Developing Countries, Trade-Related Agenda, Development and Equity, South Centre, July 2001; Organisation for Economic Co-operation and Development (OECD), Directorate for Food, Agriculture and Fisheries, Trade Directorate, Appellations of Origin and Geographical Indications in OECD Member Countries: Economic and Legal Implications, OM/AGR/APM/TD/WP(2000)15/FINAL; Dwijen Rangnekar, Geographical Indications : A Review of Proposals at the TR IPS Council, UNCTAD, June 2002; P.J. Heald, Trademarks and Geographical Indications: Exploring the Contours of the TRIPs Agreement, 29 Vand. J. Transnat'l L. 635 1996; W PO Symposium on the International Protection of Geographical Indications in the Worldwide Context, Hungary, October 1997; South Africa, September 1999; Montevideo, November 2001.

24 See W.M. Landes and R.A. Posner, Trademark Law: An Economic Perspective, 30J. of Law \& Eco. $265,1987$. 
i.e. different enough from other marks used in a similar product context. Only a distinctive mark can point the consumer to a distinctive product.

The search-cost reduction argument can be placed in a broader framework. Market conduct is critically determined by information, but in any given market the possession of information is usually asymmetric. In other words, parties to a prospective transaction dispose of unequal levels of information about the product concerned. There is an information asymmetry between the seller who knows everything about the product--and the buyer, who knows less about it. As a result the bargain is less than optimally efficient, but arriving at information symmetry is costly. Trade marks reduce the cost involved in overcoming the asymmetry - certainly in the case of experience good - -by providing the repeat customer with a relevant source of information indicating consistency of origin and characteristics of goods. Trade marks thus render markets more efficient.

\section{Criticism of the Search-Cost Reduction Theory}

Critics of the search-cost reduction theory contend that brands or trade marks, in reality, do not inform the rationally maximizing consumer, but rather influence the emotionally driven consumer by enabling "perception advertising". ${ }^{25}$ The brand or mark is manipulated by its owner, shrewd perception advertising imbues the brand, and by association the product, with properties the consumer imagines to be desirable. This allows the trade-mark owner to set a higher price for the marked goods, generating higher returns. The consumer is prepared to pay more, not because she discerns, via the brand or mark, the higher quality of the underlying goods, but because the goods are rendered subjectively more desirable by their association with a heavily promoted brand or mark. This means that even though the brand or mark may be distinctive, the underlying goods are not necessarily so. They could well be quite homogenous, the only difference lying in the way they are perceived, or in their branding. This critical perspective does not support enhanced efficiency; it also undermines the differentiation theory of trade marks considered below.

\section{E. Differentiation and Diversification}

An alternative, though co-extensive, approach focuses instead on differentiation as a market strategy. Imagine a market without legal protection of trade marks; what incentive is there for a seller to augment the quality of her product? Why attempt to increase rents by selling different goods at a higher price if differentiation can be undermined by freeriding competitors who mislead consumers by copying brands? Only in the presence of trade-mark protection is there an effective incentive to produce

25 Perception advertising is aimed at creating an artificial perception of the goods in consumers' minds rather than a realistic understanding of the goods' characteristics. 
higher quality goods that can sell at a higher price. Thus a system of trade-mark protection is essential to encourage the production of a variety of goods at varying quality levels and varying prices, resulting in greater consumer satisfaction and efficiency. In the absence of legal protection for marks, all producers would logically tend to provide the lowest cost goods at the lowest price, with the only differentiation flowing from natural advantages. Thus distinctive marks will lead the consumer to distinctive products; differentiation results in diversification.

\section{F. Trade Marks and Industrial Organization}

Another approach emphasizes the role of trade marks in industrial organization. In an industrial economy, production and consumption of goods are organizationally and geographically dis-integrated. Horizontal integration produces economies of scale, and vertical dis-integration produces efficiencies through specialization. Increased specialization means that the tasks of producing the necessities of life are rarely performed by their ultimate consumers. Whereas the subsistence farmer produces many of the goods she will consume, or a villager purchases direct from a local farmer, the factory or office worker is dependent on a longer and more complex chain of supply and exchange to obtain consumables such as food.

Trade marks enable a producer to communicate directly and efficiently with the ultimate consumer in the presence of supply chain complexity. By way of the protected mark the producer provides a direct and consistent message, saving the costs of overcoming the information asymmetry by direct communication, and thus altering the parameters of industrial organization. The trade mark enables specialization in the roles of production, distribution and consumer sale. The greater the distance between producer and consumer, the more important brand protection will be. In a global economy the distance has increased markedly, even if communication methods are constantly improving.

\section{G. Transaction Costs}

But as well as enabling supply chain specialization, trade-mark protection increases horizontal efficiencies, because the ability to license a mark increases a firm's opportunities to realise efficiencies in production and distribution. Contracting, on the basis of property rights established $a$ priori, reduces transaction costs. Branding allows cost-effective centralization of promotion and advertising, whereas production can be geographically and organizationally dispersed. Trade marks thus allow consistency in expansion over a number of differentiated markets with the most cost-efficient and rational allocation of production. Transport and distribution costs are reduced because standardized production can be effectively managed in close proximity to markets. 
Transaction costs are generally reduced by a Register-based property system, ownership is established a priori, subject to objective criteria, as is validity. The system of examination reduces the number of disputes, and the cost of resolution. At the very least, some costs are spread over the community as a whole, or the community of users of the right concerned (i.e. trade-mark owners in general) rather than fully borne by a given firm.

\section{H. Trade Marks as Barriers to Entry}

But registered trade marks have a downside; differentiation acts as an effective barrier to entry and thus suppresses competition. This requires registered-trade-marks law to strike a careful balance in terms of the scope and extent of legal rights. Economides ${ }^{26}$ posits that trade marks act as a barrier to entry because an established reputation will cause consumers to prefer the goods with known trade marks to those with the unknown trade mark of a new entrant. The known-brand owner will be able to command a premium for his product, and wilt be encouraged to increase its quality to retain the reputation he has built and keep out competitors. Hence, differentiation is sometimes said to be the most efficient, low-cost barrier-to-entry strategy for a firm. ${ }^{27}$

However, although established differentiation raises entry barriers, it simultaneously makes market entry more attractive because of the premium return that the producer with an established reputation is observed to obtain. According to Economides, trade-mark protection creates a tendency toward proliferation of marks. As long as the market is dynamic, the overall price effect for the market segment may be tempered by the discount pricing of new entrants - i.e. the premium price for quality goods is offset by the discounted price for new entrant goods. However, this is not so if the market is static. Presumably it will also not be so if the market power of the established brands allows them to match or outlive discounting by new entrants. Again, a balance must be struck in terms of the ability of established trade-mark owners to exclude new entrants, so as to prevent loss of efficiencies of scale in production and supply. ${ }^{28}$

26 See N. Economides, The Economics of Trademarks, 78 Trademark Reporter 523, 1988; see also J.S. Bain, Barriers to New Competition, Chapter IV, Product Differentiation Advantages of Established Firms as Barriers to Entry, Harvard University Press, 1956, at 114 et seq.; see further E.H. Chamberlin, The Theory of Monopolistic Competition, Chapter IV, The Differentiation of the Product: Monopolistic Competition, Harvard University Press, 1959, at 56 et seq. In Helen Norman's article Skechter's "The Rational Basis of Trade-Mark Protection" Revisited, she points out that Shechter's seminal article in the Hatward Law Review which posited that a trade mark is not so much important as au indication of origin, but "to create and retain custom" (at 191), published in Perspectives on IP, Vol. 7, TradeMarks Retrospective, S\&M, 2000. She points out that this has little impact on judges in the U.K., who continue to interpret the Trade Marks Act narrowly without considering "what the proper basis for protection ought to be" (at 192).

27 See Bain, ibid., at 142143.

28 Trade-marks law achieves this balance by various means, for instance, prohibition on registration of descriptive terms" the genericness defence' defences relating to use in good faith, such as comparison advertising; the requirement of trade-mark use etc. 


\section{The Economics of Language}

It is a well-established principle that a private monopoly in ordinary terminology has anti-competitive effects. For that reason, descriptive terms or devices cannot be registered as trade marks. Other traders must not incur additional costs when using ordinary descriptors. This applies as well to geographical terms. If the use of a term is descriptive of its origins it cannot be registered as a trade mark; others in the area must be able to describe the geographical origin of their goods or services. ${ }^{29}$ If it were otherwise, a wholly artificial barrier to entry could be erected.

The law of trade marks also reduces the barrier effect of registration by restricting rights in terms that become descriptive by the defence of "genericness". When a brand becomes equated with a certain kind of product, as opposed to a certain source, the owner loses monopoly rights by the law rendering it unenforceable or by removing it from the Register. The barrier to entry for competitors is then lowered.

Traditional "language economics" emphasizes that the monopolization of inherently distinctive, artificial terms can not be of great concern, because the supply of invented terms is essentially infinite. ${ }^{30}$ But others (the "critical view") argue that not all distinctive marks are equal at the outset; some work better in the market and are therefore more desirable, and the supply of more desirable trade marks is not infinite. ${ }^{31}$ Some marks may be inherently more striking, or more readily remembered. The point is even more significant because trade-mark rules do not absolutely prohibit descriptiveness. Many registered marks have a descriptive element but are still sufficiently distinctive to be registered. For others with a descriptive element, the mark owner will have to prove a level of acquired distinctiveness, in other words, establish consumer recognition.

The critical view tends to require a stricter adherence to the rules of trade-marks law that distinguish terms that can and terms that cannot be monopolized; above all, the requirement of trade-marks use $\mathrm{32}^{\mathbf{3 2}}$ and the requirements of proof of distinctiveness. Underlying the critical view is a realisation that the question of monopoly in a mark is not simply an abstract question relating to words alone. The significance of monopolies in words relates not to the market for words as such but to the competition in markets for goods described by those words.

This is significant in terms of registered GIs, where there is no real-use requirement, there is no defence of genericness, and inherently descriptive terms are, per definition,

29 See, for example, Clark Equipment Co. v. Registrar of Trade Marks, (1964) 111 CLR 511 ; Oxford University Press" v. Registrar of Trade Marks', (1990) 24 FCR 1.

30 See Landes and Posner, supra, footnote 24, at 271

31 See A.L. Carter, The Trouble with Trademark, 99 Yale Law Journal 759, 1990.

32 As to the importance of adherence to this requirement of use, see M. Davis, Death of a Salesman's Doctrine: A Critical Look at Trademark Use, 19 Georgia Law Review 2, 233, 1985. 
registrable without showing any proof of reputation. Implications flow in relation to access to markets for the kinds of goods marked with registered GIs.

\section{APPLYING THEORY TO REGISTERED GIS}

\section{A. GIs and Search-Costs}

Information asymmetry is most significant in the context of experience goods, i.e. goods that are not testable at purchase. In modern times most foodstuffs, including wine and spirits, are experience goods and non-testable. This is even more so for the products for which GI protection is most ardently sought, such as wines, which have a reputation wider than just local. In that sense, legal protection of signs used in relation to these types of goods is prima facie acceptable within the broader framework of the search-cost reduction theory.

This acceptance is tempered by whatever credence one may give to the critical view, i.e. that the brand does little more than enable perception advertising, influencing the emotions of the consumer rather than the consumer as rational maximizer. To overcome this type of criticism, and maintain search-cost reduction, an ideal system might, by regulation, attempt to ensure that consumers' perception of the brand closely approximates real, as opposed to perceived, product qualities. Registered GI systems that impose product standards as well as origin requirements arguably do just that. However, if use of the registered GI is not subject to product standards but only origin rules, then the alleged masking effect may potentially be enhanced.

Individual registered trade-mark owners decide the quality of their products independently. The law does not stop brand-owners from diluting the quality of the branded goods. But the trade-mark owner is indirectly restrained by commercial selfinterest; the risk that the brand's reputation, and hence ability to generate surplus rents, is destroyed in the process of quality dilution. Registered GIs are different in that they are collectively owned. Whereas the registered trade mark's individual owner is indirectly and commercially restrained from varying the quality of goods excessively over time, the commercial self-interest of one legitimate user of a GI may not be sufficient to protect all its other legitimate users.

Thus, if left unregulated, the independent commercial decision of one registered GI user to reduce quality may affect its value for all other legitimate users. The risk cannot be overcome by relying on commercial self-interest alone, since one local user may be tempted to trade-off long-term damage to the GI's reputation, that might also accrue to other users, against short-term returns that might accrue to him through "misusing'the GI. ${ }^{33}$ The only way to overcome this risk is to restrict the tendency of users of a registered GI to vary the underlying quality of the product. In the absence of such regulation the

33 What is meant by "misuse" might, for example, be the selling of goods with inferior ingredients under the GI. 
search-cost reduction effect of a GI may be reduced: the symbol is rendered unreliable, as the behaviour of its multiple legitimate users is less predictable.

\section{B. Product Differentiation, Consumer Protection and Transaction Costs}

In a more general sense, by analogy with trade marks, the economic purpose of GIs is to encourage diversification in food supply. In terms of rural produce, application of idiosyncratic, traditional and labour-intensive processes results in product variations and higher prices. Value-adding in rural locations will result in the loss of economies of scale compared to bulk supply and industrial processing. Allocation of legal rights in relation to relevant signifiers enables producers to translate higher production costs into higher returns, while avoiding free-riding.

The grant of GI registration is one possible allocation system. But why prefer it over simply relying on a general action against commercial misrepresentation? One reason has already been mentioned: to prevent dilution in the presence of multiple right holders. Another significant reason relates to transaction costs. The general advantages of a priori system of GI registration are the same as for trade marks, as canvassed above.

Additionally, in the context of GIs, a difficulty arises in determining who amongst competing genuine claimants, usually from contiguous or homonymous areas, has the right to use a regional signifier. A considerable saving may flow from delineating the precise margins of geographical areas a priori, rather than ex post, in the context of a dispute. A social premium results, as the advantages of pre-delineation of an area will extend to a wider number of parties than just those involved in a dispute.

\section{The Uniqueness Principle}

The product differentiation approach to trade-mark theory demands that distinctive trade marks mean distinctive goods. Trade marks enable the mark owner to produce goods that differ from the common standard. However, nothing other than commercial necessity (the need to preserve her reputation) requires the trade-mark owner to make a product that is different. A registered trade mark is not a guarantee of the uniqueness of the marked product. In terms of GIs, the differentiation argument is taken a step further. A region has unique geographic and human characteristics, not replicable in any other region; these characteristics imbue regional agricultural products with unique qualities. Since goods emanating from another region must, by definition, be different, there can be no justification for using the same geographical term to describe goods from a different region. It will ipso facto be a misrepresentation to do so, so a priori rights make more sense than an action which requires - in fact superfluous - proof of misrepresentation. In that way there is a much stronger link between the distinctiveness of the GI and the uniqueness of the underlying product, and an even stronger justification for a priori, broad proprietary rights. 
However, this argument depends on the validity of the proposition that a product can and does uniquely reflect local characteristics and cannot be replicated elsewhere, an issue discussed further below. But if one accepts the uniqueness principle, it again demands a system that has stringent product-standard controls and adheres strictly to the requirement of geographic origin. Otherwise the GI cannot be guaranteed to represent the unique characteristics of the goods of the originating region, and extensive a priori rights will not be warranted.

\section{Registered GIs and industrial Organization}

As mentioned earlier, a key factor in the growth of brands and their legal regulation is the separation between consumer and producer. During the industrial era this distancing process accelerated rapidly for manufactured goods, but arguably less for agricultural goods. But now that agriculture has embraced modern packaging, transport and global trade, the separation between consumer and producer has rapidly increased. In such circumstances, registered GIs are one method by which a small-scale producer, far removed geographically and structurally from the consumer, can reach through to that consumer with a consistent quality message. Naturally, that can also be done by way of ordinary trade marks, and the choice between trade mark and GI-based strategies is a significant question.

GI registration also promotes rationalization of costs of promotion, because advertising expenditures can be shared by a number of non-competing producers. If those producers already supply homogenous products, duplication of the costs of promotion is avoided. The tentative conclusion flowing from the above is that there may be a reasonably sound theoretical basis for a system of registered GIs. But this is only the case if such a system requires, first, adherence to strict rules of origin, and second, strict product standards. However, a system of registered GIs with such characteristics suffers from significant drawbacks, as analysed below. But before addressing the drawbacks in strong GI protection, it is important to re-visit one of the central tenets of GI registration along the European model: the uniqueness principle.

\section{THE DRAWBACKS INHERENT IN A SYSTEM OF REGISTERED GIS}

\section{A. Distinctive Signs for Distinctive Products}

A critical distinction between GIs and comparable legal regimes lies in the approach to terms that become generic. This distinction is significant in the divide between the EU and some New World States about future global GI protection. A core justification proffered for GI protection without a genericness defence is the uniqueness principle: the name of a region, when used by producers outside the region, is unavoidably misleading because those products could never have the unique regional characteristics required. 
The name of a region can, a fortiori, never become a general descriptor of a category or kind of goods.

The uniqueness principle is not universally accepted. Taking the example of wine, it may be the case that if grapes come from a very small denomination that is geographically homogenous and distinct, and the wine is consistently produced by idiosyncratic methods, it cannot be replicated anywhere else. This proposition is difficult to test, but it must become more doubtful the larger the denomination and the more varied the geography. For other products, the proposition may be even more doubtful. For cheese, for instance, there is unlikely to be a discernable difference between products from different regions as long as certain transferable methods are observed in the derivation and making. ${ }^{34}$

Production methods may, in general, be far more significant to the characteristics of agricultural products than geographic origin. While geographic characteristics are obviously not transferable, but are rarely absolutely unique, even the most unusual methods of growing and processing crops can be copied, and skills transferred or learned. In many ways the latter is exactly what did happen when wine-makers from Europe established themselves in the New World, for example, in Australia. Accepting this has far-reaching consequences, as it not only undermines the uniqueness principle it also undermines the consumer-protection function of registered GIs. In other words, whereas there may be no difficulty in accepting that the law should be structured to ensure that traders correctly indicate where goods originate (actions against misrepresentation), it is harder to accept that the law should reinforce the arguably questionable perception that goods bear unique characteristics because of their place of origin (strong GI registration systems). Criticism of the uniqueness proposition is particularly significant in the context of the prohibition on any form of generic use of a GI.

Even if one accepts that a product can uniquely reflect the conditions of its geographical origins, there are still significant concerns with a registered GI system along European lines.

\section{B. Barriers to Market Entry, Competition Distortions and Protectionism}

Proponents of GI registration argue that it has pro-competitive effects, as it enables smalland family-based rural industries to resist industrial consolidation. Thus, continuous use of traditional and labour-intensive methods in areas with special characteristics will only take place in the presence of strong property rights in GIs, also serving social, industrial, economic and regional policy goals.

But this comes at a cost. Opponents would stress that strong GI protection distorts

34 See W. Moran, Rural Space as Intellectual Property, Political Geography 12,263, 1993, at 274. 
competition as it supports inefficient rural production and land-use and prevents efficiencies in agricultural production that will deliver both variety and lower prices.

The distortions to competition caused by strong GI rights principally affect producers (just) outside the boundaries of the region, producers within the region intending to adopt uncertified production techniques, and producers intending to use the GI descriptively in markets where it has, in fact, become generic. If the conditions of geographic origin and product standards are strictly adhered to, the distorting effect is at least partially offset by countervailing benefits to consumers. But if the rules ensuring observance of these conditions are not sufficiently stringent, there is a risk of "slippage": from benign intervention in agricultural production into detrimental protectionism. This has been considered in some decisions of the European Court of Justice (ECJ). In Sekt and Weinbrand, the ECJ ruled that to turn indirect generic names into indirect GIs was discriminatory. ${ }^{35}$ To warrant GI registration distinctive qualities and characteristics were required, ${ }^{\mathbf{3 6}}$ otherwise the purpose of imposing the restrictions flowing from registration is not fulfilled. However, in Exportur it was held that a distinctive reputation was sufficient. $^{37}$

This reinforces the argument that registration of GIs should be conditional on the strict observance of effective quality standards and on the products reflecting the unique characteristics of the region. It is essential to prevent slippage in the formulation and application of the legal rules that ensure observance in practice of these two conditions. Any system of GI registration must be critically evaluated from this point of view. The legitimacy of the system, in the face of its distorting effects, can only flow from the uniqueness of the products of a region, and from a guarantee of consistent quality. ${ }^{38}$

\section{Competition, Territoriality and Rural Policy}

Moran stresses that policy in relation to legal protection of GIs reflects the way in which governments "provided differential opportunities for their citizens and industries". ${ }^{39}$ Doubting the link between geographical features and quality of wines, he sees rather that unsubstantiated assertions about environmental influences are "used to assert and justify

35 Case 12/74 Sekt and Weinbrand, [1975] ECR 181.

36 See J. Armistead, Whose Cheese is it Anyway? Correctly Slicing European Regulation concerning Protections for Geographic indications, 10 Transnat'1 L. \& Contemp. Probs. 303, 2000, at 309-310.

37 Exportur, [1992] Ecr $<1-5529$. Armistead, ibid. at 322, argues that without the quality link, the protection of a GI may amount to protectionism.

38 However, some commentators, such as Moran, supra, footnote 34, go further, arguing that the distorting effects always outweigh the putative benefits, because the claim that a product can uniquely reflect the characteristics of a region is unfounded. No region is, in fact, unique; and it is always possible to obtain products with the stone characteristics from other regions, since the inputs and processes which give rural produce their special characteristics can be replicated in many other places. If that is the case, then the granting of GI protection, certainly where the term has become generic for many consumers, is arguably a form of protectionism. If both location A and B can make and supply the product, which is known by the name of region A, why should only A be allowed to do so?

39 W. Moran, Wine Appellations as Territory in France and California, 83 Annals of the Association of American Geographers, Vol. 4, 1993, 694-717, at 695. 
political and territorial control, and thereby influence the distribution of the industry". ${ }^{40}$

In the prototypical case of wine, the question can be put: "Are wine delimitations really determined by geography, or rather by politics?" Moran's answer undermines the cardinal principle underlying appellation of origin (AOC) -type registration of GIs in the wine industry: that it can be empirically proven that the quality of wine is determined directly by the geography of an area. He argues that the location of prime wine-growing regions in France has moved over time "partly as the result of the regional localization of political power." ${ }^{41}$ Moran notes that there is a striking unity between political entities (i.e. political subdivisions such as Communes) and AOC-entitled entities. The quality of wines in certain regions has, in Moran's opinion, more to do with consistent attempts at improving techniques and adapting them to the environment, which have resulted in optimization over time. Many more regions than are now established would be open to this process, but it is not in the interests of established higher-level AOC regions to encourage such transfers of skills and processes.

Whether or not one accepts that geography uniquely determines quality, Moran's analytical framework draws attention to the territorial effects of strong GI regulation. Other industries, or alternative land uses, are displaced by the registration system, ${ }^{42}$ and land values are maintained in areas which otherwise may have limited agricultural uses. It would seem that in fertile agricultural areas which are or could be put to competing productive land uses, a registration system will entrench existing uses that are not necessarily optimal, and experimentation with different crops or rural products will be discouraged.

On the other hand, GI registration is also used to reduce agricultural overproduction. An increase in the areas under AOCs in France - in areas in the south where few AOCs existed - has coincided with policies of the EU directed at eliminating lower-quality vines in a bid to reduce over-production of wine. ${ }^{43}$ But Moran stresses that it is dificult for new areas to compete with established AOCs, even if they produce quality wines. ${ }^{44}$ Thus, established AOC areas benefit from a distortion in competition in the market for wines of similar quality. This use of registered GIs to limit territorial overproduction is significant. In countries that suffer from rural over-production, whether because of subsidization or for other reasons, it may make sense; however, countries whose primary aim is self-sufficiency in agricultural products and maximization of efficient allocation of rural resources, might take a different view.

40 Ibid., at 694.

41 Ibid., at 705.

42 Furthermore, producers within an area who do not want to adhere to the specifications, cannot use the name of the place where they are based; this imposes a restriction on their ability to trade and compete.

43 See Moran, supra, footnote 39, at 699.

44 Ibid., at 709. 


\section{Flexibility v. Legitimacy}

Registered GIs thus distort competitive land use and rural production, protecting certain land uses, production methods and forms of industrial organization at the expense of potentially more efficient alternatives. Crucial to counterbalancing these effects is adherence to stringent product standards and rules of geographic origin. Otherwise the system may amount to little more than complex, distorting and impenetrable protectionism. However, such stringent regulation imposes detrimental rigidities. Hence, every system of GI registration struggles to accommodate the tension between, on the one hand, the legitimacy derived from strict quality and origin rules, and on the other hand, the desire to assuage the detrimental effects of rigid regulation by adopting more liberal rules relating to geographical origin and product standards. Somewhere the balance must be struck. Arguably, because of the scepticism about geographic uniqueness and the natural variations within even the smallest geographical areas, to ensure that GIs fulfil their function of a meaningful quality signal, the emphasis should be on rigid adherence to consistent product standards. ${ }^{45}$ Relaxation of geographical origin rules may be acceptable, even if only within very limited parameters.

The detrimental rigidities that flow from a registered GI system are restrictions on supply, on methods of production, and on technological innovation. These are further explored below.

\section{E. Geographic Origin Rules as Restrictions on Supply}

A registered GI system does not only suffer from restrictions on the methods that can be applied in rural production, but also on the volume of production. ${ }^{\mathbf{4 6}}$ This flows both from the requirement of geographic connection, and from the need to adhere to production levels by restraining production standards. ${ }^{47}$ The focus in this Section is on the requirement of geographical origin; in the next Section the focus is on innovation and restrictive production standards. Geographical limits restrain the ability of a local industry to respond flexibly to natural variations in production levels. It may also impede flexible responses to market signals, in particular variations in demand in the presence of a relative inability to vary price.

45 This does not mean that it is not important to maintain the transaction cost advantages by having clear a priori delineations. Rather, it may be the case that products should still be entitled to use a GI even if some of the production steps occurred outside the region concerned. This point is illustrated further below by way of a brief comparison between the Australian and the French system of GI registration for wines.

46 Indeed, according to some, this is virtually the main point of the system: to limit overproduction; see, for instance, Moran, supra, footnote 34.

47 See Moran, supra, footnote 39, where he analyses the production level/quality level connection in wine production, and the fact that one of the principle aims of adherence to certain agricultural methods is reducing production. It is well illustrated by the AOC/AOP system, which requires all phases-production, processing and preparatiof- to occur within the geographical area. 
Agricultural industries are subject to meteorological and other natural hazards, and thus production levels within a given area, particularly if it is small, can be irregular and unpredictable. Strong GI registration systems leave no effective response for this kind of eventuality, because the product cannot be imported from outside. The loss of returns in a low-yielding season can only partly be offset by the price premium that can be charged in the better seasons. In any case, producers incur costs in dealing with an uneven income spread. The problem is at its most acute if GI registration requires all elements of production, processing and preparation to occur within the area as, for instance, for European protected designations of origin (PDOs) ${ }^{48}$ By contrast, European "protected" GI (PG1) requirements are inherently more flexible: only one facet of production, processing or preparation need take place within the designated area. ${ }^{\mathbf{4 9}}$ If this is processing or preparation, then obviously the product can be sourced from outside, thus alleviating the supply problem.

Yet products may suffer in terms of reputation if the link with a locality is more tenuous, which may not satisfy consumers looking for a strong geographical identity. In a broad policy sense, the risk is that the connection becomes entirely tenuous and quite misleading, and the aims of the system are effectively subverted. If the justification for strong GI protection is that the growers of a certain area are exclusively entitled to use a geographical term because only their area can impart certain unique qualities to the goods concerned, then the PGI approach is questionable. Product produced elsewhere should not have the GI used in association with it, because it could not possibly have the same characteristics as the product produced within the GI area.

If greater flexibility exists in terms of sourcing products, then it is even more essential that strict processing and preparation standards are observed. From this perspective, the system of registered PGIs under Regulation 2081/92 in the EU at least requires adherence to production "specifications" which will ensure consistency over time. ${ }^{\mathbf{5 0}}$ However, rigorous rules in specifications concerning processing and preparation themselves also limit production levels, and thus place constraints on growth of the rural industry concerned. This poses a general problem of inflexibility in product development and a stifling of innovation, which is further examined below.

\section{F. Registered GIs, Innovation and Diffusion}

If a legitimate system of GI registration requires, in addition to rules of origin, a specification which ensures consistent application of production standards, the negative

48 As based on Regulation 2081/92, 14 July 1992, on the protection of geo 'aphical indications and designations of origin for agricultural products and foodstuffs, O.J. L 208, 24 July 1992. See further below.

49 Perversely, one could say that the Australian system, which has larger and more varied delineations, thereby reduces the risks of irregular production levels within the denomination.

50 There is a proviso, in particular in relation to wine: the consistent application of certain techniques is no guarantee for consistent quality over the years. This is particularly the case in regions with chronologically inconsistent weather and growth patterns. 
result is a significant brake on innovation. From one point of view, this might be seen not as a problem, but as the essential benefit of registered GIs: to resist innovation, i.e. to grant some level of protection for traditional production methods. This may well be an advantage where traditional production methods, localized and artisanal in character, are well established. However, if that is not the case, a system of GIs with rigid specifications has far fewer attractions. In other words, where there are no long-established artisanal production methods, the trade-off in terms of constraints on innovation may render registered GIs unattractive - compared, for instance, to corporate brands - for the establishment of new value-added rural industries. ${ }^{\text {51 }}$

But even where localized and traditional production methods are well established, the brake on innovation is a serious concern. Even if a system of registered GIs allows some innovation, the collective consultations and agreement required are necessarily cumbersome and slow, preventing rapid adaptation to changing competitive environments. The system is also inherently conservative and it is, therefore, somewhat contradictory to emphasize the potential for innovation that is theoretically present. While innovation is not impossible, it is likely to fall within a very narrow band of likely changes. ${ }^{\mathbf{5 2}}$ Innovation in this sense is not only technological or related to agricultural science or new crops, but also adaptation to new market conditions.

An interesting case in point is the comparison often drawn between the Australian and the French wine industries. The latter, at least in those areas covered by AOCs, is prisoner to rigid production methods, vested rural interests and established local land values. Competition by way of innovation within the national wine industry is suppressed or distorted, leaving the door open for foreign competition which relies on innovation and flexibility to respond to consumer demand.

In effect, in terms of competition in the market for foodstuffs, under a system of registered GIs all the competitive eggs are in one basket: regional brand promotion. Innovation as a way of competing effectively is limited in those areas governed by registered GIs, and is displaced to areas outside the delimitations. ${ }^{53}$ As shown above, those areas are at a competitive advantage in terms of innovation, but their quality message will have a difficult time breaking through.

A final point about flexibility. Constraints on innovation and limits on supply are closely linked questions; agricultural innovation includes experimenting with the planting and production of new crops. A system which restricts the ability to innovate or experiment in this manner may be of little concern in the context of well-established patterns of

51 Absolute protection also gives a degree of monopoly over the way the product is made, in particular in relation to indirect GIs.

52 Innate conservatism springs from a preference for the known over the uncertain. Moran describes how French wine-makers returned to the same varietals after the phylloxera crisis, and did not take the opportuuity to assess alternatives and innovate: see Moran, supra, footnote 39, at 700.

53 Moran puts it as follows: "Countries adopting systems of geographic indications which are too rigid or restrictive may find that they undermine the innovation and flexibility that is one foundation of the success of their industries.": see Moran, supra, footnote 39, at 716. 
planting and production resulting from experimentation over wider areas for a long period of time. Moran points out that in Europe, there was a long period of experimentation with the planting of vines in different areas, often for personal consumption on mixed farms, before production for commercial purposes became concentrated in certain naturally adapted regions. ${ }^{\mathbf{5 4}}$ However, in New World agriculture that process of experimentation is ongoing, and it would perhaps be counter-productive to place artificial barriers in its path. In other words, diffusion of production will be stymied; furthermore, so will, arguably, the diffusion of optimal production techniques. Moran illustrates it as follows:

"The appellation system itself ensures that the methods of exploiting the natural advantages for viticulture and wine-making built up in Burgundy over centuries cannot be captured by regions other than Burgundy."

\section{G. Licensing and Exploitation of Registered}

On a different level, the rigidity inherent in a registered GI system expresses itself in legal terms in a prohibition on licensing. In contrast, registered trade marks can be relatively freely licensed. It has been pointed out above that the licensing of trade marks reduces transaction costs, and enables rationalization of production and economies of scale and stability in supply in widely diverse markets.

The inability to license a GI has some detrimental economic effects. The owner of a registered trade mark can engender competition amongst potential licensees who manufacture branded goods and generate economies of scale in production. ${ }^{\mathbf{5 6}}$ Similar efficiencies could flow if a registered GI could be attached to goods that have not been produced, processed or prepared in the delineated region, but simply have characteristics that have become associated with a certain geographic term over time. ${ }^{57}$ For instance, if the only requirement is that the raw product originates in the region, then firms outside the region can be licensed to process or prepare it, thus engendering economies of scale, and competition between processors. Alternatively, if the product must be processed within the region, but not necessarily produced, then again there can be economies of scale and efficiencies in licensing producers outside the region to produce the product to be processed within it, and so on. Of course, if there was no requirement for geographical connection but only for adherence to the specifications, then even more flexible licensing practices would be possible. But those circumstances bring a return to the same point made above - if there is no geographical link with an area, there is no justification for strong GI rights. The system becomes gradually more protectionist, and one might as well rely on an ordinary registered trade mark or certification mark.

54 See Moran, supra, footnote 34, at 266.

55 See ibid., at 273.

56 For instance, because a single factory produces goods for various unrelated brand owners, to be sold under different brand names.

57 Moran makes reference to "Bleu de Bresse" a non-registered cheese GI licensed for production in New Zealand; see Moran, supra, footnote 34, at 274. 
From the above one might reasonably conclude that in the absence of an established system of GI registration, the arguments in favour of establishing a separate regulatory structure which enforces rules of origin and product standards do not clearly outweigh the arguments against. This is certainly the case in the absence of agricultural overproduction, and where there is no established policy of State intervention or high levels of regulation of agricultural industries. It is also the case if the broader regulatory context supports modernization, flexibility and innovation in rural industries. In the light of this conclusion, the development of GI registration in Europe provides some insights into the historic dynamics now at play in the negotiations within the WTO Agreement on TradeRelated Aspects of Intellectual Property Rights (TRIPS) concerning the multilateral register and expansion of higher level protection to foodstuffs other than wine.

PART 1I: In Part II of this article some aspects of the historical development and present regulatory structures of GI registration in Europe and the New World are examined. This examination will highlight the fact that current proposals for increased GI registration worldwide are part of a historical continuum, and that a registration system along EU lines is potentially onerous and invasive. 